\title{
LTD Stirling engine with regenerator. Numerical and experimental study
}

\author{
N. Martaj ${ }^{1, a}$, R. Bennacer ${ }^{2}$, L. Grosu ${ }^{3}$, S. Savarese $^{4}$ And A. Laaouatni ${ }^{1,5}$ \\ 1 EPF-École d'Ingénieurs, 2 rue F. Sastre, 10430 Rosières-près-Troyes, France \\ 2 ENS-Cachan Dpt GC/ LMT, 61 Av du Président Wilson, 94235 Cachan Cedex, France \\ 3 LEME, Université Paris Ouest, 50 rue de Sèvres, 92410 Ville d'Avray, France \\ 4 Armélio, 7 avenue de l'Atlantique, Les Ulis, 91955 Courtabœuf Cedex, France \\ ${ }^{5}$ LAEPT, Université Cadi Ayyad, Faculté des Sciences Semlalia, Marrakech, Morocco
}

Received 4 October 2015, Accepted 14 March 2016

\begin{abstract}
In this paper, a model of a low temperature difference (LTD) Stirling engine with regenerator is presented. The equations governing the heat transfer and the compressible fluid dynamics are solved numerically as a coupled system, including the ideal gas state equation, Navier Stokes equations and energy balance. The engine cycle induces flow compression, expansion and regeneration in free volumes and through porous media. The present developed CFD model makes possible to obtain the instantaneous values of the physical parameters (pressure, temperature, velocity, density, etc.). With these obtained values, the continuous $p$ - $V$ cycle can be analysed which leads to the mechanical work calculation. The results of the simulation concerning an engine with regeneration is compared to those obtained in previous work by an engine without regeneration and validated with experimental data obtained under similar conditions without regeneration. The preliminary results show the important improvement due to the engine regeneration operation and the related regenerator porosity effect allowing the reduction of the pressure drop and viscous dissipation.
\end{abstract}

Key words: Stirling engine / regenerator / porous media / CFD

\section{Introduction}

The various Stirling engine types, are driven by "hot gases" $[1-3]$ with contribution of external heat which leads to great flexibility in use. Within the framework of sustainable development, they constitute an alternative to be taken into account for the effective conversion of renewable energies into mechanical work, with high theoretical efficiency [4-6]. They are able to operate with low differences of temperature (LTD) between both heat sources and thus convert wasted heat into various processes [7-13]. Their geometrical configuration can be very simple. However, the regenerator, which has the role to absorb and to release heat at the adequate cycle phase in order to produce output work with efficiency close to that of the Carnot cycle, is a critical machine element [14-18].

The use of the refrigerating Stirling machine, using air or another inert gas as working fluid, represents an interesting alternative to mitigate the problem of the ozone layer destruction by organo-chlorinated refrigerants [19-21]. This cycle has, theoretically, a performance

\footnotetext{
${ }^{a}$ Corresponding author: nadia.martaj@epf.fr
}

coefficient equal to that of Carnot cycle, assuming a perfect regenerator.

The theoretical cycle is composed of two isothermal processes within heat exchangers, and two isochoric processes associated to the working gas flow through the regenerator. The regenerator consists, in general, of a porous or fibrous material with great permeability and high thermal conductivity and specific heat.

Previous works were published concerning thermodynamic optimization using several levels of analysis: 0D finite time thermodynamic [22], finite size finite speed of revolution thermodynamics [23], Direct Method [24,25], multi-objective optimization [26], 1D model [27,28].

The output power and work of these machines are strongly related to the geometrical and physical parameters (dimensions, heat transfer properties, temperatures of the sources, characteristic of the regenerator...). The studied LTD Stirling engine is a "Gamma" type one. It has separate hot, cold and regeneration volumes. These volumes are delimited by the hot and cold plates of the exchanger and the two pistons: the working piston and the displacer (Fig. 1). 


\section{Nomenclature}

\begin{tabular}{|ll|}
\hline$c_{p}$ & Specific heat at constant pressure $\left[\mathrm{J} \cdot \mathrm{kg}^{-1} \cdot \mathrm{K}^{-1}\right]$ \\
$k$ & Viscosity coefficient $\left[\mathrm{kg} \cdot \mathrm{m}^{-1} \cdot \mathrm{s}^{-1}\right]$ \\
$K$ & Permeability $\left[\mathrm{m}^{2}\right]$ \\
$k s$ & Conductivity $\left[\mathrm{W} \cdot \mathrm{m}^{-1} \cdot \mathrm{K}^{-1}\right]$ \\
$N$ & Engine revolution speed $\left[\mathrm{rev} \cdot \mathrm{min}^{-1}\right]$ \\
$p$ & Pressure $[\mathrm{Pa}]$ \\
$Q$ & Heat $[\mathrm{J}]$ \\
$\dot{Q}$ & Heat flow rate $[\mathrm{W}]$ \\
$T$ & Temperature $[\mathrm{K}]$ \\
$t$ & Time $[\mathrm{s}]$ \\
$r$ & Specific gas constant $\left[\mathrm{J} \cdot \mathrm{kg}^{-1} \cdot \mathrm{k}^{-1}\right]$ \\
$u$ & Velocity $\left[\mathrm{m} \cdot \mathrm{s}^{-1}\right]$ \\
$W$ & Work [J] \\
\hline & $\quad$ Greek symbols \\
\hline$\varepsilon$ & Porosity [-] \\
$\eta$ & Dynamic viscosity, $\left[\mathrm{kg} \cdot \mathrm{m}^{-1} \cdot \mathrm{s}^{-1}\right]$ \\
$\lambda$ & Thermal conductivity $\left[\mathrm{W} \cdot \mathrm{m}^{-1} \cdot \mathrm{K}\right.$ \\
$\mu$ & Efficiency [\%] \\
$\theta$ & Crankshaft angle $[\mathrm{rad}]$ \\
$\rho$ & Density [kg.m $\left.{ }^{-3}\right]$ \\
$\tau$ & Viscous stress tensor $\left[\mathrm{kg} \cdot \mathrm{m}^{-1} \cdot \mathrm{s}\right.$ \\
\hline & $\quad$ Subscript \\
\hline $\mathrm{h}$ & Hot \\
$\mathrm{c}$ & Cold \\
$\mathrm{d}$ & Displacer piston \\
$\mathrm{eq}$ & Equivalent (porous media) \\
$\mathrm{g}$ & Gas \\
$\mathrm{p}$ & Working piston \\
$\mathrm{s}$ & Solid matrix \\
$\mathrm{w}$ & Wall \\
$\mathrm{t}$ & Total \\
\hline
\end{tabular}

The working piston and the displacer, are out of phase a quarter of revolution as the related evolution is represented in Figure 2. The working gas flows from the upper hot space to the lower cold zone through the porous displacer which acts as a regenerator.

The principal objective of this work is to develop a CFD model for the Stirling engine with a porous regenerator in order to quantify the possible improvements. We used a multiphysics CFD simulation of the conjugate solid/gas heat transfer involving both thermal and aerodynamic processes (Navier-Stokes equations, equation of energy and ideal gas equation) on moving domains including the regenerator, hot space and cold space.

This model will be a tool to optimize the engine operation by the choice of regenerator material and its geometry.

\section{Mathematical model}

The studied engine is mainly composed of 3 spaces (hot, cold and regeneration) as represented under 2D axisymmetric (Fig. 1b).
It is assumed that the flow in the engine is laminar due to the operating conditions (low speed, small paths). The thermo-physical properties of gas such as density, specific heat and thermal conductivity are considered depending on the instantaneous local temperature and pressure. It is supposed that thermal properties (density, specific heat) of the porous material (regenerator) and its porosity are uniform and constant.

Another assumption consists in neglecting radiation processes due to the weak temperature difference, so the heat transfer is mainly governed by conduction and convection.

The simulated evolution of the energy, mass and momentum transfer of the compressible flow in this LTD engine with porous regenerator is achieved with a multiphysics software using a moving mesh. The simulated considered engine allows access to the instantaneous values of the local variables as pressure, temperature, velocity and density.

The global exchange is on several subdomains:

- flows on the hot and cold sides (gas),

- plates in contact with the hot source and the cold sink (solid),

- porous regenerator (solid and gas interface).

These corresponding energy equations for the gas, solid and regenerator, respectively are given below:

$$
\begin{aligned}
\left(\rho \cdot c_{p}\right)_{\mathrm{g}} \cdot \frac{\partial T}{\partial t}+\nabla\left(\left(\rho \cdot c_{p}\right)_{\mathrm{g}} \cdot u \cdot T\right)= & \left(k_{\mathrm{g}} \cdot \nabla T\right) \frac{D p}{D t} \\
& -\tau: \nabla u \\
\left(\rho \cdot c_{p}\right)_{\mathrm{w}} \cdot \frac{\partial T}{\partial t}= & \nabla\left(k_{\mathrm{w}} \cdot \nabla T\right)+Q \\
\left(\rho \cdot c_{p}\right)_{\mathrm{eq}} \cdot \frac{\partial T}{\partial t}+\nabla\left(\left(\rho \cdot c_{p}\right)_{\mathrm{g}} \cdot u \cdot T\right)=\nabla & \left(k_{\mathrm{eq}} \cdot \nabla T\right) \\
& +\frac{D p}{D t}-\tau: \nabla u
\end{aligned}
$$

where $\left(\rho . c_{p}\right)_{\mathrm{eq}}$ and $\left(\rho . c_{p}\right)_{\mathrm{g}}$ are porous matrix and fluid equivalent heat capacity, respectively.

The last term of Equation (3) represents viscous power and is given by:

$$
-(\tau: \nabla u)=\mu \varphi_{u}
$$

where $\varphi_{u}$ is related to dissipation given in cylindrical coordinates $(r, z)$.

$$
\begin{array}{r}
\varphi_{u}=2\left[\left(\frac{\partial u_{r}}{\partial r}\right)^{2}+\left(\frac{u_{r}}{r}\right)^{2}+\left(\frac{\partial u_{z}}{\partial z}\right)^{2}\right]+\left[\frac{\partial u_{r}}{\partial z}+\frac{\partial u_{z}}{\partial r}\right]^{2} \\
-\frac{2}{3}\left[\frac{1}{r} \frac{\partial}{\partial r}\left(r u_{r}\right)+\frac{\partial u_{z}}{\partial z}\right]^{2}
\end{array}
$$

In absence of this term $\left(\varphi_{u}=0\right)$, all the forms of energy implied in the equation of energy (kinetic, internal and potential) are interchangeable. The case $\varphi_{u}>0$ means that there is transfer from mechanical to thermal energy.

These previous partial derivative Equations (1) to (5) form a system of five nonlinear and coupled equations. 


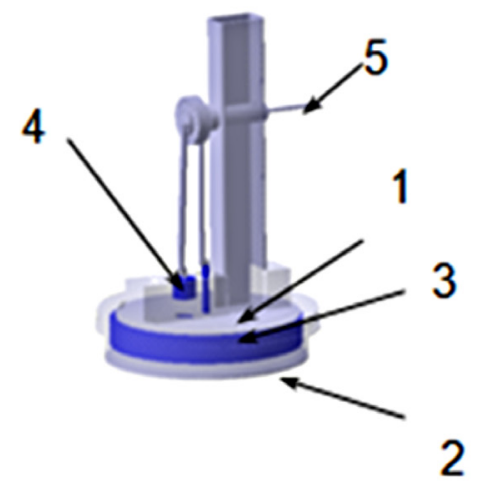

$-a-$

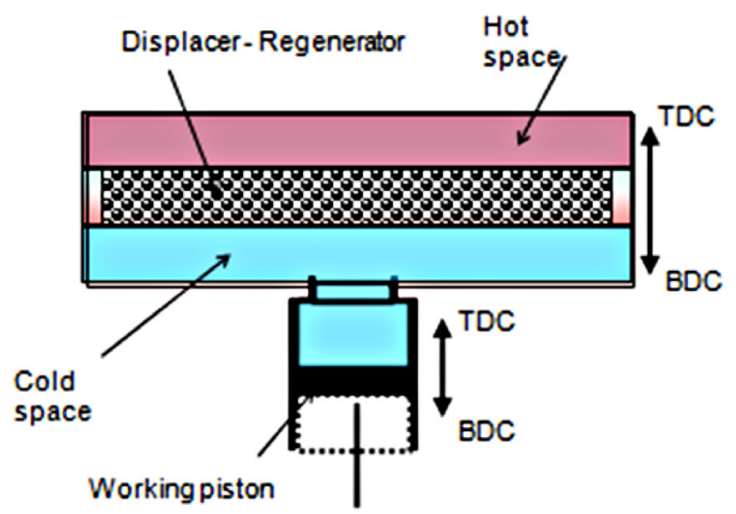

$-\mathrm{b}-$

1. cold source,

2. hot source,

3. displacer piston,

4. working piston,

5. driving shaft

Fig. 1. Gamma LTD Stirling engine (a) Prototype scheme. (b) 2D axial symmetry used for the numerical modelling.

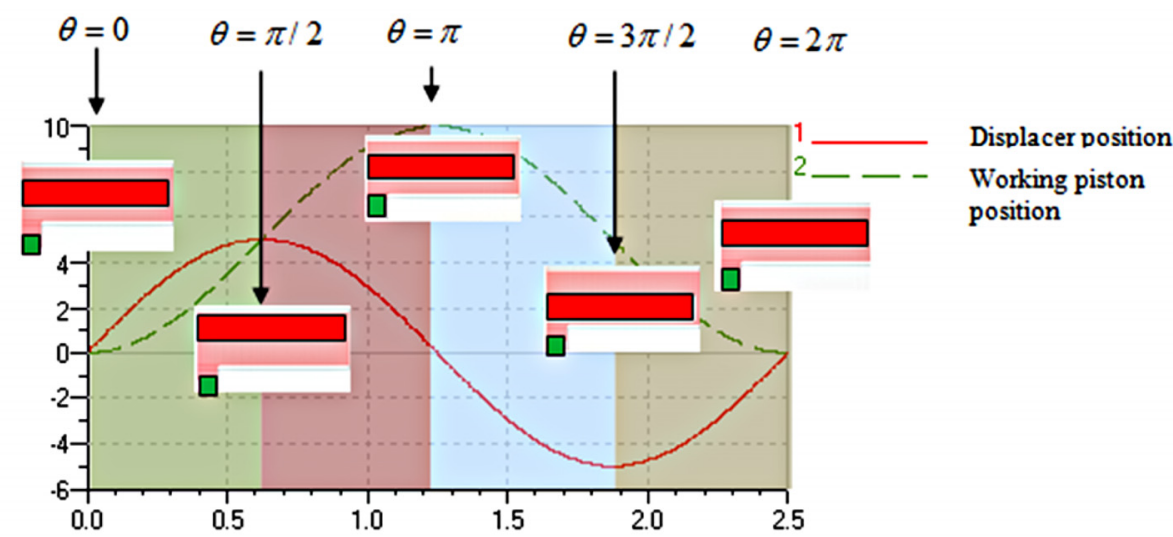

$\theta=0$ Initial position of the pistons: point 1 on figure 5 displacer at half stroke and working piston at BDC (maximum total volume)

Fig. 2. Pistons positions evolution: displacer (1) and working piston (2) versus time.

This system is actually impossible to solve analytically but discrete approximate solution is reachable by numerical method.

The evolution of the linked pressure, velocity and density are governed by the Navier-Stokes equations, continuity and thermodynamic laws. The mass conservation and momentum are as follows:

$$
\begin{gathered}
\frac{\partial\left(\varepsilon_{g} \rho_{g}\right)}{\partial t}+\nabla\left(\rho_{g} u\right)=0 \\
\left(\frac{\rho_{g}}{\varepsilon_{g}}\right) \frac{\partial u}{\partial t}+\beta \rho_{g} u . \nabla u=\nabla\left[-p I+\eta\left(\frac{1}{\varepsilon_{g}}\right)\right. \\
\left.\times\left(\nabla u+(\nabla u)^{T}\right)-\left(\frac{2 \eta}{3}-k\right)(\nabla u) I\right]+F
\end{gathered}
$$

where $\varepsilon=\beta=1$ in the clear fluid (hot and cold volumes, gas) and $\varepsilon=\varepsilon_{g}$ and $\beta=\left(\frac{\eta}{K}\right)$ in the porous environment. $\varepsilon_{g}$ is the regenerator porosity, $\rho$ the fluid density and $u$ the gas velocity.

The geometrical and physical properties of the used regenerator are the apparent density $\rho_{s}$, thermal conductivity $k_{s}$, and specific heat $c_{p}$.

To solve the system of partial derivative equations described previously, with prescribed boundary and initial conditions, it is also necessary to provide a complementary equation known as equation of state which connects the thermodynamic properties of the fluid and is given by:

$$
p=\rho_{\mathrm{g}} r T
$$

The boundary conditions applied to the limits of the considered system (Fig. 1b) are summarized below. 
Table 1. Thermophysical properties and operating conditions used in the simulation.

\begin{tabular}{ccccccccc}
\hline & $\begin{array}{c}T_{w h} \\
(\mathrm{~K})\end{array}$ & $\begin{array}{c}T_{w c} \\
(\mathrm{~K})\end{array}$ & $\begin{array}{c}P_{s} \\
(\mathrm{~Pa})\end{array}$ & $\left.\begin{array}{c}N \\
(\text { rev.min }\end{array}{ }^{-1}\right)$ & $\begin{array}{c}\rho_{s} \\
\left(\mathrm{~kg} \cdot \mathrm{m}^{-3}\right)\end{array}$ & $\begin{array}{c}\varepsilon_{s, g} \\
-\end{array}$ & $\begin{array}{c}k_{s} \\
\left(\mathrm{~W} \cdot \mathrm{m}^{-1} \cdot \mathrm{K}^{-1}\right)\end{array}$ & $\begin{array}{c}c_{p} \\
\left(\mathrm{~J}_{\mathrm{kg}} \mathrm{kg}^{-1} \cdot \mathrm{K}^{-1}\right)\end{array}$ \\
\cline { 2 - 9 } Values & 301 & 290 & 101325 & 24 & 7850 & $0.4 \rightarrow 0.6$ & 44.5 & 475 \\
\hline
\end{tabular}

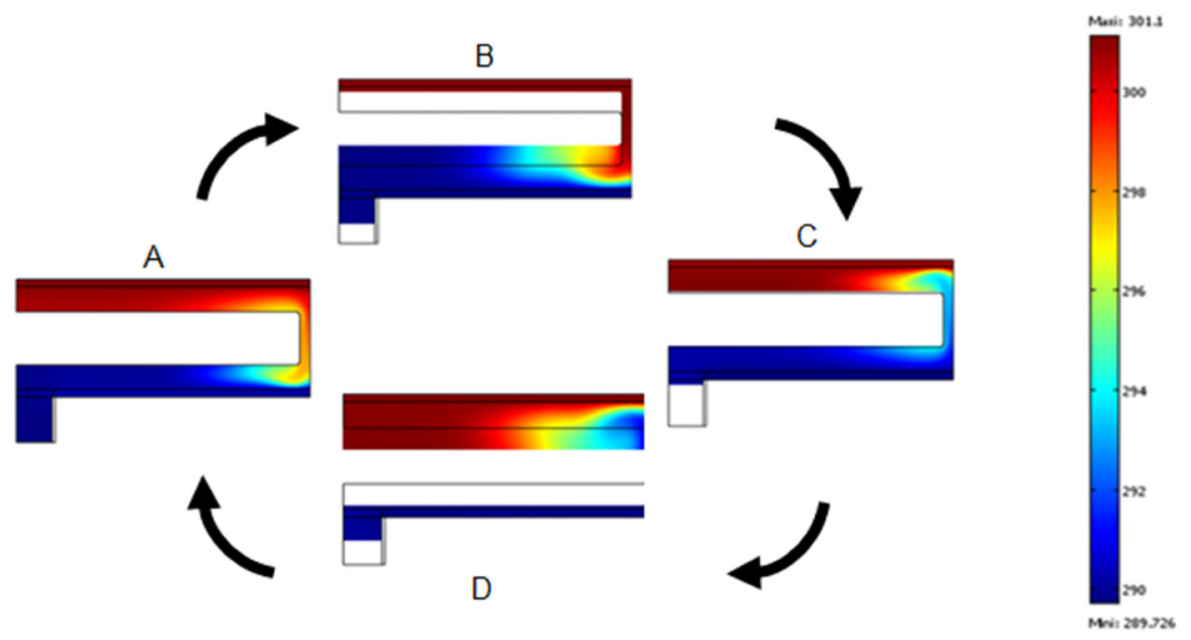

Fig. 3. Temperature fields in various points of a cycle without regenerator.

- External horizontal surfaces temperatures are the hot and cold plate temperatures respectively with $T_{w h}$ and $T_{w c}$.

- The interface transfer between these plates (internal) and the fluid are given by: $\left(k_{\mathrm{s}} \nabla T_{\mathrm{s}}\right) n_{\mathrm{s}}+\left(k_{\mathrm{g}} \nabla T_{\mathrm{g}}\right) n_{\mathrm{g}}=$ 0 .

- The working piston and the displacer velocity are related to the spatial position and respectively given by $u=\partial z_{\mathrm{m}} / \partial t$ and $u=\partial z_{d} / \partial t$.

- Concerning the vertical boundaries of the solution domains, a condition of symmetry on the central axis of the engine $(r=0)$, such conservative condition is expressed as $-n\left(-k \nabla T+\rho C_{\mathrm{p}} u T\right)=0$.

\section{Results and discussions}

The numerical simulations are used to display the characteristics of a working gas (air) for the considered and previously defined LTD Stirling engine with regeneration, in its hot and cold spaces as well as in the regenerator.

The performances of the engine depend on several parameters, such as regeneration efficiency governed by the geometrical and physical characteristics of the used porous media (porosity, thermal conductivity of the porous matrix, etc.). Calculations were carried out for a $138 \mathrm{~mm}$ regenerator diameter, fixed speed rotation, fixed hot and cold temperature as summarised in Table 1.

The study of the porous regenerator properties on the engine performances allows the identification of the optimal parameter values where the compromise between the positive heat recovery and the negative pressure drop is achieved.
Figure 3 illustrates the 2D temperature field variation corresponding to the different engine position represented in Figure 2. It is obvious from this result the complex local heat exchange on the horizontal plates resulting from the induced gas flow. The exchange is mainly assumed by the vicinity of the connecting hot to cold region. Such area is consequence of the involved flow resulting from the global coupling.

The corresponding flow field at the same characteristically positions are represented in Figure 4. The flow is laminar on the most domains but turbulent in the connecting region due to the velocity increase consequence of the section decrease. Some irreversibility is amplified by the appearance of multiple vortex in both hot and cold region. The present using displacer regenerator will reduce the vortex intensity, the turbulent level and will also increase the efficient heat exchange area.

Such previously presented reversible Stirling cycle (Fig. 5) is composed, when idealised, of 2 isothermal processes (heating/cooling line 1-2 and 3-4) and 2 isochoric ones (storage/release of heat, at constant volume, to- and from the regenerator). Such regenerator element allows heat recovery between 2-3 and 4-1 during gas transition between the hot and cold cell. Such recovery improves the efficiency by increasing the produced work.

The real cycle is not with perfect isochore and isotherm transformations as illustrated in Figure 6. This figure compares the cycles obtained with regeneration $(2 \mathrm{D}$ simulation) and without regeneration obtained numerically and experimentally.

The comparison of the cycles obtained numerically (red line) and experimentally (black) without regenerator exhibit a global satisfactory. As expected the $P-V$ diagram fit more on volume which is a geometrical constraint 


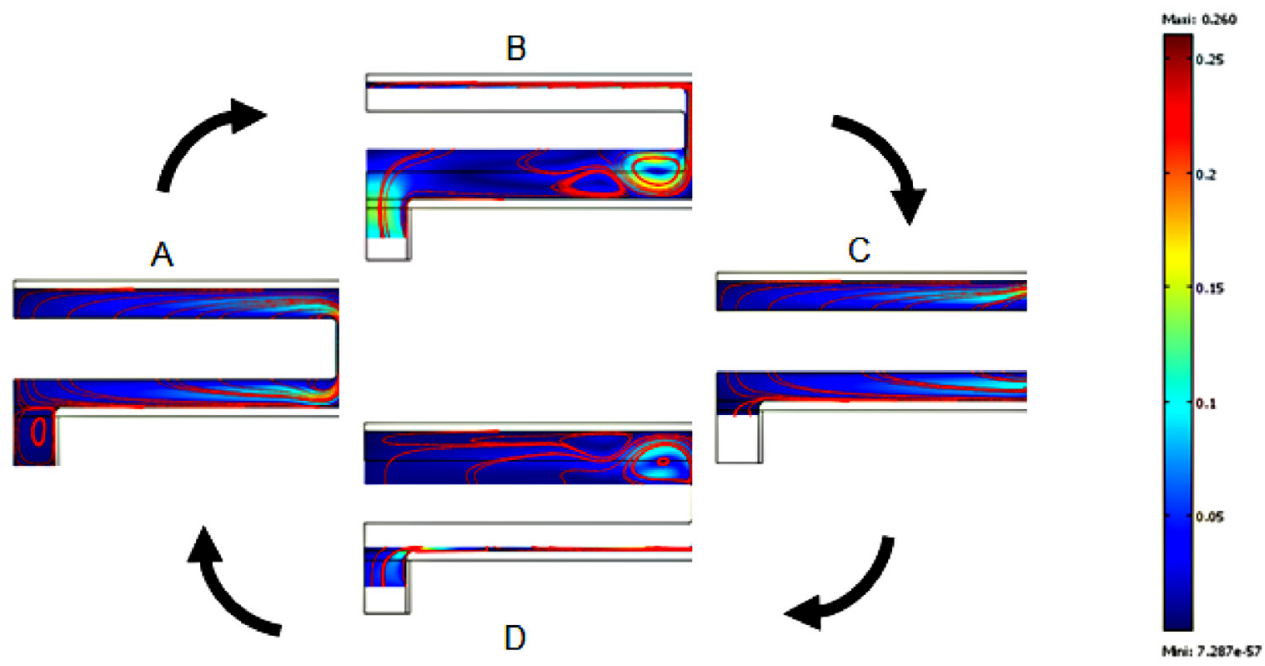

Fig. 4. Flow fields in various points of a cycle without regenerator.

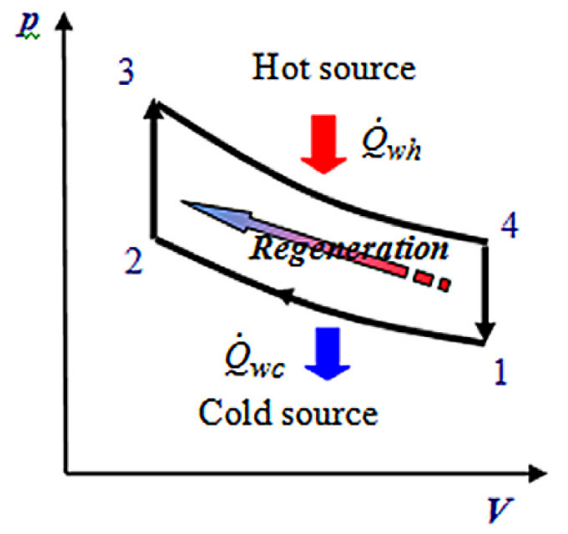

- Process between points 1-2: the cold gas is compressed by the working piston ( $\theta$ from 0 to $\pi / 2$ )

- Process between points 2-3: the displacer drives out gas towards the hot cell where it warms up with constant volume on the regenerator ( $\theta$ from $\pi / 2$ to $\pi$ )

- Process between points 3-4: expansion of gas by pushing the working piston ( $\theta$ from $\pi$ to $3 \pi / 2)$

- Process between points 4-1: the displacer drives out gas towards the cold cell( $\theta$ from $3 \pi / 2$ to $2 \pi$ )

Fig. 5. Diagram of Stirling engine theoretical cycle.

and less on pressure which is a real coupling between the thermal exchange, the flow and fluid state. Indeed the simulated case with regenerator shows, in comparison to the without, the positive effect of regeneration on the work cycle. The experimental diagram contained between the two numerical results shows that, despite the absence of a dedicated regenerator in the experimental engine, a "natural" regeneration effect probably exists due to the non-adiabaticity of the connecting wall between hot and cold chambers and the thermal inertia of the walls.

The case "without regenerator" means that the working gas only flows through the passage between the displacer piston and the displacer cylinder; hence porosity of the displacer is unity in this case.

The cycle obtained by $2 \mathrm{D}$ simulation with regeneration approaches better the theoretical reversible cycle of the Stirling engine. Concerning the used regenerator, we can underline the important fact of the porosity of the used media (Fig. 7).

The increase of the porosity induce positive effect due to the shear stress decrease and the corresponding pressure drop but the material thermal inertia decreases inducing lower regeneration ability. The present underlined compromise is illustrated in Figure 4 where the evolved $P-V$ cycle passes from the reference cases without regeneration (porosity of 1 ) to a better cycle with porosity decreases and a maximum obtained for porosity of 0.4 .

The corresponding obtained for the different analysed porosity are summarised in Table 2 .

We notice that work increases when porosity decreases, in the considered range $(0.4$ to 1.0$)$ and the efficiency is better. 
N. Martaj e al.: Mechanics \& Industry 18, 305 (2017)

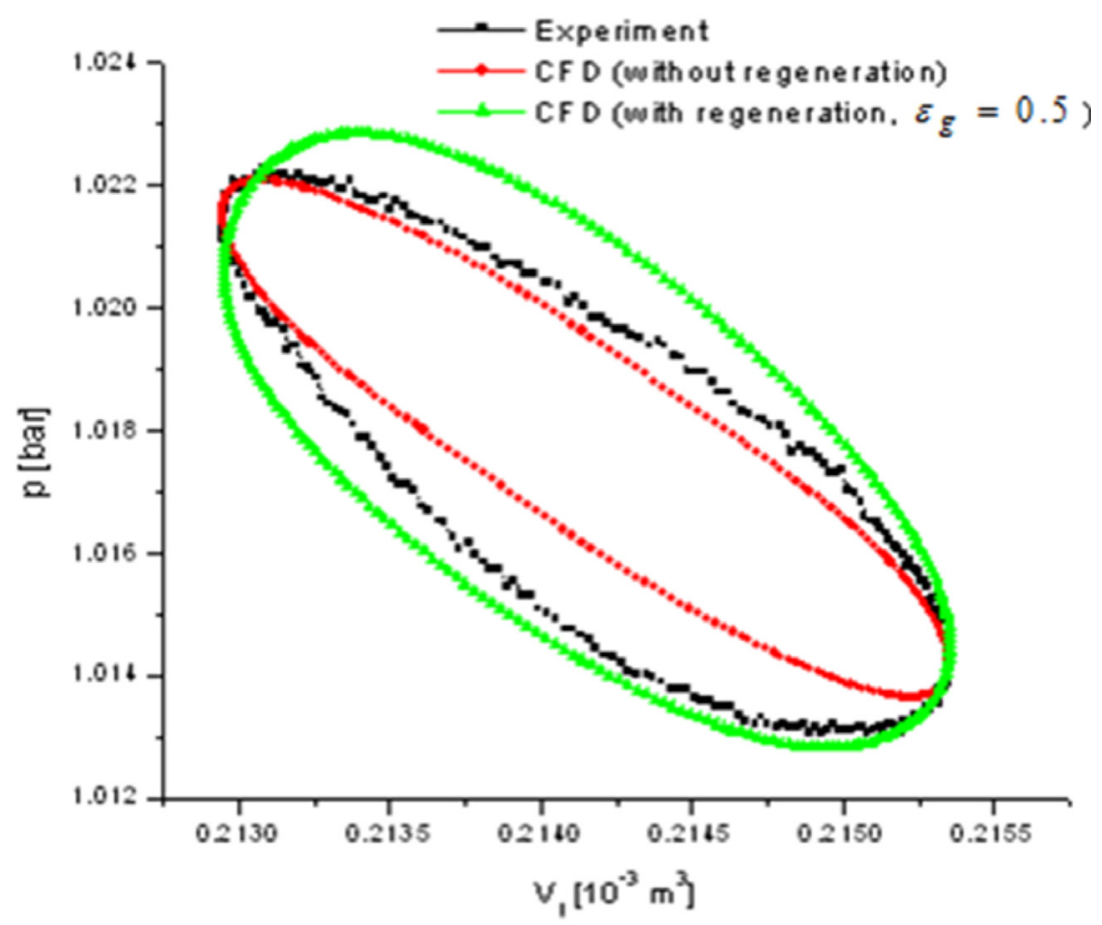

Fig. 6. Comparison of $p-V$ diagrams for the different approaches.

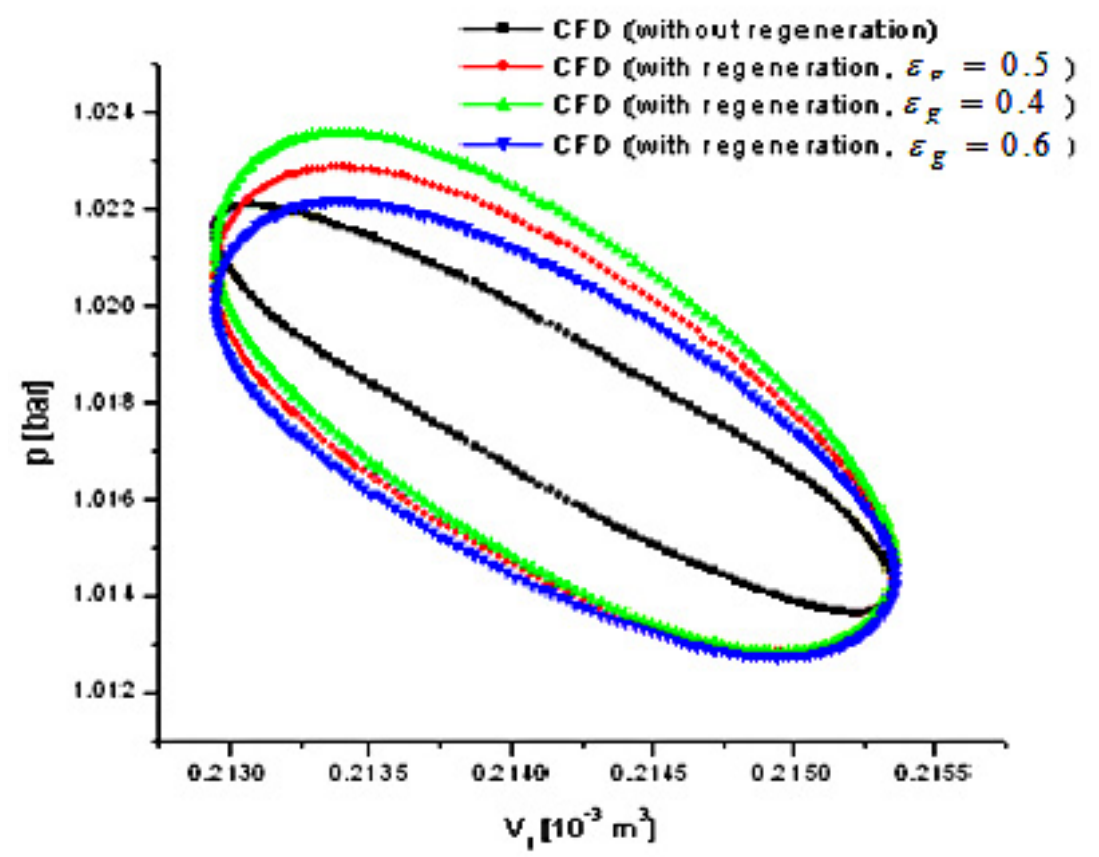

Fig. 7. $(p, V)$ diagram obtained by $2 \mathrm{D}$ simulation for: $\varepsilon_{g}=0.6, \varepsilon_{g}=0.5, \varepsilon_{g}=0.4$ and $\varepsilon_{g}=1$.

Table 2. Comparison of the obtained results.

\begin{tabular}{cccc}
\hline$\varepsilon_{g}$ & $\begin{array}{c}W \\
(-)\end{array}$ & $\begin{array}{c}\dot{Q}_{w h} \\
(\mathrm{~J} / \mathrm{cycle})\end{array}$ & $\begin{array}{c}\mu \\
(\mathrm{W})\end{array}$ \\
\hline 1.0 & $0.8 \times 10^{-3}$ & $0 \mathrm{~A} 94$ & 0.408 \\
0.6 & $1.3 \times 10^{-3}$ & 0.718 & 0.455 \\
0.5 & $1.4 \times 10^{-3}$ & 0.720 & 0.488 \\
0.4 & $1.5 \times 10^{-3}$ & 0.722 & 0.522 \\
\hline
\end{tabular}

\section{Conclusion}

The present study shows that numerical tools allows the coupling of the fluid state equation, the energy conservation on several sub-domains, the fluid flow on the clear domain (pure fluid) and on the porous media (regenerator) under the moving machine pieces. The presented 
porous regeneration approach permits to tend toward the theoretical reversible cycle of Stirling engine.

By a systematic and rational sweeping of geometrical parameters (stroke and bore of the pistons) and physical parameters, we compute the resulting heat transfer and fluid flows. The continuous knowledge of such local variables values, the power outputs was determined. The effect of the chosen regenerator porosity on the produced work was underlined. A real machine improvement was identified and the present step shows the way for a more complete optimization. Indeed the operation will help in modifying the experimental setup and more particularly, for the choice of the regenerator material and geometry.

\section{References}

[1] N. Martaj, P. Rochelle, L. Grosu, R. Bennacer, S. Savarese, Moteur Stirling à faible différence de températures (LTD): confrontation simulations numériques et expérimentation, Congrès SFT, 3-6 juin 2008, Toulouse, 729-735

[2] I. Urieli, D.M. Berchowitz, Stirling Cycle Machine Analysis, Adam Hilger LTD, Bristol, 1982

[3] G.T. Reader, C. Hooper, Les machines Stirling, E \& F.N. SPON, New Fetter Lane, London, 1983

[4] P. Nika, F. Lanzetta, Développement d'une machine frigorifique Stirling de petite taille, adaptée à des niveaux thermiques modérés, Journal de physique 5 (1995) 835861

[5] J.R. Senft, Theoretical limits on the performance of Stirling engines, Int. J. Energy Res. (1998) 991-1000

[6] C.H. Cheng, Y.J. Yu, Numerical model for predicting thermodynamic cycle and thermal efficiency of a beta-type Stirling engine with rhombic-drive mechanism, Renew. Energy (2010) 2590-2601

[7] R. Gheith, F. Aloui, M. Tazerout, S. Ben Nasrallah, Experimental investigations of a gamma Stirling engine, Int. J. Energy Res. 36 (2012) 1175-1182

[8] B. Kongtragool, S. Wongwises, Performance of lowtemperature differential Stirling Engines, Renew. Energy 32 (2007) 547-566

[9] Der Minassians, A Stirling engine for low-temperature solar-thermal-electric power generation, University of California, Ph.D. thesis, Berkeley, 2007

[10] M. Feidt, K. Lesaos, M. Costea, S.Petrescu, Optimal allocation of HEX inventory associated with fixed power output or fixed heat transfer rate input, Int. J. Appl. Thermodyn. 5 (2002) 25-36

[11] B. Kongtragool, S. Wongwises, Investigation on power output of the gamma configuration low temperature differential Stirling engines, Renew. Energy 30 (2005) 465476

[12] A. Robson, Development of a computer model to simulate a low temperature differential Ringbom Stirling engine, Thermo- and GFD modelling of Stirling machines, Proceedings 12th International Stirling Engine Conference, Durham, 2005, pp. 350-357

[13] P. Rochelle, L. Grosu, Analytical solutions and optimization of the exoirreversible Schmidt cycle with imperfect regeneration for the 3 classical types of Stirling engine, Oil Gas Sci. Technol. 66 (2011) 747-758
[14] A.J. Organ, The Regenerator and the Stirling Engine, Wiley, 1997

[15] S.K. Andersen, H. Carlsen, Per Grove Thomsen. Preliminary results from simulations of temperature oscillations in Stirling engine regenerator matrices, Energy (2005) 1371-1383

[16] I. Tlili, Y. Timoumi, S. Ben Nasrallah, Thermodynamic analysis of Stirling heat engine with regenerative losses and internal irreversibilities, Int. J. Engine Res. (2007) $45-56$

[17] F. Wu, L. Chen, C. Wu, F. Sun, Optimum performance of irreversible Stirling engine with imperfect regeneration, Energy Convers. Manage. 8 (1998) 727-732

[18] M.B. Ibrahim, Z. Zhang, R. Wei, T.W. Simon, Gedeon D. A 2-D CFD model of oscillatory flow with jets impinging on a random wire regenerator matrix, IEEE, 2004, pp. 511-517, ISBN 0-7803-7296-4

[19] J.T. Wang, J. Chen, Influence of several irreversible losses on the performance of a ferroelectric Stirling refrigeration-cycle, Appl. Energy (2002) 495-511

[20] W.M. Clearman, J.S. Cha, S.M. Ghiaasiaan, C.S. Kirkconnell, Anisotropic steady-flow hydrodynamic parameters of microporous media applied to pulse tube and Stirling cryocooler regenerators, Cryogenics (2008) 112121

[21] E. Ataera, H. Karabulut, Thermodynamic analysis of the V-type Stirling-cycle refrigerator, Int. J. Refrigeration (2005) 183-189

[22] L.G. Chen, F.R. Sun, Advances in Finite Time Thermodynamics: Analysis and Optimization, Nova Science Publishers, New York, 2004

[23] L. Grosu, P. Rochelle, N. Martaj, An engineer-oriented optimization of Stirling engine cycle with Finite-size finite-speed of revolution thermodynamics, Int. J. Exergy 2 (2012) 191-204

[24] L. Grosu, S. Petrescu, C. Dobre, P. Rochelle, Stirling refrigerating machine. Confrontation of Direct and Finite Physical Dimensions Thermodynamics Methods to Experiments, Int. J. Energy Environ. Econ. 3 (2012) 195207

[25] S. Petrescu, M. Costea, C. Harman, T. Florea, Application of the Direct Method to irreversible Stirling cycles with finite speed, Int. J. Energy Res. 26 (2002) 589-609

[26] M.H. Ahmadi, A.H. Mohammadi, Dehghani S. Evaluation of the maximized power of a regenerative endoreversible Stirling cycle uising the thermodynamic analysis, Energy Convers. Manage. (2013) 561-570

[27] N. Martaj, L. Grosu, P. Rochelle, A. Mathieu, M. Feidt, Simulation of a Stirling engine used by a micro solar power plant: 0-D modelling, comparison with 1-D modelling, Environ. Eng. Manage. J. (under press)

[28] S.K. Andersen, H. Carlsen, Per Grove Thomsen, Preliminary results from simulations of temperature oscillations in Stirling engine regenerator matrices, Energy (2005) 1-13 